Published in "Chronobiology International 27 (4 ): 768-781, 2010 "

which should be cited to refer to this work.

\title{
CONES ARE REQUIRED FOR NORMAL TEMPORAL RESPONSES TO LIGHT OF PHASE SHIFTS AND CLOCK GENE EXPRESSION
}

\author{
Anna Dollet, ${ }^{1,2}$ Urs Albrecht, ${ }^{3}$ Howard M. Cooper, ${ }^{1,2}$ and \\ Ouria Dkhissi-Benyahya ${ }^{1,2}$
}

${ }^{1}$ INSERM, U846, Stem Cell and Brain Research Institute, Department of Chronobiology, Bron, France

${ }^{2}$ University of Lyon, Lyon I, Lyon, France

${ }^{3}$ Department of Medicine, Division of Biochemistry, University of Fribourg, Fribourg, Switzerland

In mammals, non-visual responses to light involve intrinsically photosensitive melanopsin-expressing retinal ganglion cells (ipRGCs) that receive synaptic inputs from rod and cone photoreceptors. Several studies have shown that cones also play a role in light entrainment, photic responses of the suprachiasmatic nucleus (SCN), pupil constriction, and sleep induction. These studies suggest that cones are mainly involved in the initial response to light, whereas melanopsin provides a sustained input for nonvisual responses during continued light exposure. Based on this idea, we explored the effects of the absence of middle-wavelength (MW)-cones on the temporal responses of circadian behavior and clock gene expression in light. In mice lacking MW-cones, our results show a reduction in behavioral phase shifts in response to light stimulations of short duration at 480 and $530 \mathrm{~nm}$, but no alteration for short-wavelength (360-nm) light exposures. Similarly, induction of the period gene mPer 1 and mPer2 mRNAs in the SCN are attenuated in response to light exposures of mid to long wavelengths. Modeling of the photoresponses shows that mice lacking MW-cones have an overall reduction in sensitivity that increases with longer wavelengths. The differences in photic responsiveness are consistent with the idea that cones provide a strong initial phasic input to the circadian system at light-onset and may confer a priming effect on ipRGC responses to sub-threshold light exposures. In summary, the contribution of MW-cones is essential for the normal expression of phase shifts and clock gene induction by light in mammals. (Author correspondence: ouria.benyahya@inserm.fr)

Keywords Circadian system; Clock genes; Melanopsin; Phase shift; Retina; SCN

Submitted November 13, 2009, Returned for revision December 11, 2009, Accepted January 7, 2010

Source of support: This work was supported by grants from EUCLOCK (EU FP6 project 018741), Rhône-Alpes Cible, and Retina France. The authors thank F. Flamant for providing the $T R \beta^{-/-}$mouse model and C. Gronfier and L. Mure for critical reading of the manuscript.

Address correspondence to Dr. Ouria Dkhissi-Benyahya, INSERM U846, Stem Cell and Brain Research Institute, Department of Chronobiology, 18 Avenue du Doyen Lépine, F-69500 Bron, France. Tel: 33-472.91.34.87; E-mail: ouria.benyahya@inserm.fr 
In mammals, behavior, metabolism, and physiological functions are regulated on a circadian basis by an endogenous clock located in the suprachiasmatic nucleus (SCN) of the hypothalamus. To maintain synchrony with the day/night cycle, the central clock is reset (entrained) daily by environmental light. In mammals, this photic information is transmitted from the retina to target neurons in the SCN via intrinsically light-sensitive, melanopsin-expressing ganglion cells (ipRGCs) that also receive inputs from rod and cone photoreceptors (Berson et al., 2002; Hattar et al., 2002; Belenky et al., 2003; Dacey et al., 2005; Viney et al., 2007).

In mutant and transgenic mice lacking specific photopigments, altered non-visual responses to light are observed following retinal degeneration of rods and/or cones, genetic knockout of the melanopsin photopigment gene $(\mathrm{Opn} 4)$, or transgenic invalidation of rod/cone phototransduction pathways. Depending on the retinal alteration and composition of the light stimulus, the functional absence of one or more of these photopigments generally leads to deficits in light-induced phase shifts, entrainment, SCN neuronal responses, pupillary light reflex (PLR), and masking (Ebihara \& Tsuji, 1980; Lucas et al., 2003; Mrosovsky, 2003; Mrosovsky \& Hattar, 2003, 2005; Panda et al., 2002, 2003; Dkhissi-Benyahya et al., 2007; Mure et al., 2007; Drouyer et al., 2007, 2008; Thompson et al., 2008).

The results of these and other studies suggest that rods and cones contribute to the response at light-onset, whereas melanopsin provides a sustained response to continuous light exposure. The phasic input component from outer retinal photoreceptors and sustained input from ipRGCs are observed in electrophysiological retinal recordings of ipRGCs (Berson et al., 2002; Dacey et al., 2005; Schmidt et al., 2008), in SCN responses to light (Drouyer et al., 2007; Mure et al., 2007), and in pupil responses (Lucas et al., 2001; Hattar et al., 2003; Gamlin et al., 2007; Mure et al., 2009). Recently, it has also been suggested that in mice, cones are required for the initial light-dependent induction of sleep (Altimus et al., 2008). In a mouse model specifically lacking middle-wavelength $(\mathrm{MW})$-cones (maximum absorbance $=508 \mathrm{~nm}$ ), we have previously shown an abnormal phase angle of entrainment and specific deficits in phaseshifting responses to mid- and long-wavelength light pulses of different irradiances (Dkhissi-Benyahya et al., 2007). Data from this study also suggested that the absence of MW-cones altered the responses to shortduration light exposure at $480 \mathrm{~nm}$, but we did not examine temporal effects at other wavelengths.

In the present investigation, we extended this study by further exploring the consequences of the absence of MW-cones on phase shifts for light exposures of different durations at wavelengths from 360 to $530 \mathrm{~nm}$. In addition, we examined the photic induction of the period genes $m P e r 1$ 
differentially affected by the duration and wavelength of the light pulse. We hypothesized that the absence of cone photoreceptors would result in deficits in the response, in particular, for short-duration light exposures.

\section{METHODS}

\section{Animals}

The $T R \beta^{-/-}$null mice used in this study have been described previously (Gauthier et al., 1999; Dkhissi-Benyahya et al., 2007) and are characterized by the absence of MW-expressing cones. Inactivation of the $T R \beta$ gene results in impairment of auditory function, but no alteration in development, metabolism, or neurological functions has been described in these animals (Forrest et al., 1996). Heterozygous mice were derived in an inbred 129SV background. Control homozygous animals were from the same genetic background and were obtained by inter-crossing heterozygous animals. All experiments were done with male mice between 6 and 8 wks of age at the start of the experiment. Animals were housed in Plexiglas cages under a $12 \mathrm{~h} / 12 \mathrm{~h}$ light-dark (12L/12D) cycle, with food and water ad libitum. All treatment of animals was in strict conformity with current international regulations on animal care, housing, breeding, and experimentation and those of the journal for ethical biological rhythm research (Portaluppi et al., 2008).

\section{Phase-Shifting Assay}

For monitoring locomotor activity, mice were housed individually in cages equipped with passive infrared motion captors placed over the cages, and continuous data were collected in 1-min bins using a computerized data acquisition system (Circadian Activity Monitoring System, INSERM, France). Activity records were analyzed with the Clocklab software package (Actimetrics, Evanston, IL).

Singly housed male mice ( $\mathrm{n}=8$ for each genotype) were first entrained in a 12L/12D cycle for 20 days. Subsequently, animals were maintained in constant darkness (DD) at least for 10 days. Phase shifts were studied using monochromatic light pulses of an equivalent irradiance of $2.8 \times 10^{14}$ photons $/ \mathrm{cm}^{2} / \mathrm{s}$ for durations of 1,5 , and $15 \mathrm{~min}$. The data reported herein for light pulses of $480 \mathrm{~nm}$ were presented in a previous study (Figure 5, Dkhissi-Benyahya et al., 2007). We then completed this experiment by analyzing phase shifts at two additional wavelengths (360 and $530 \mathrm{~nm}$, half-bandwidth, $10 \mathrm{~nm})$ using the same exposure durations $(1,5$, and $15 \mathrm{~min})$ and the same irradiance level $\left(2.8 \times 10^{14}\right.$ photons $\left./ \mathrm{cm}^{2} / \mathrm{s}\right)$. The ultraviolet (UV) light source was a high-pressure mercury vapor 
365-nm band. Kodak neutral density filters were used to adjust the irradiance level. The order of presentation of duration and wavelength (and dark control) was randomized. The light stimulus was applied at CT16 ( $4 \mathrm{~h}$ after activity-onset). Dark controls were handled in the same way but did not receive a light pulse. The stimulator (light source and chamber) has been described previously (Dkhissi-Benyahya et al., 2000). After the light pulse, animals were returned to their home cages, and activity was monitored in DD for an additional 15-20 days before the next light pulse in order to calculate the amplitude of the light-induced phase shift. The magnitude of a light-induced phase shift was determined from the difference between the regression lines of the activity-onsets before and after the light stimulation using the built-in Clocklab functions and extrapolated to the day following the light pulse. The transient responses during the 3-4 days immediately after the pulse were discounted.

\section{In Situ Hybridization: Light Induction of mPer1 and mPer2 in the SCN}

In order to compare the sensitivity of the behavioral response of the circadian system in wild-type and MW-coneless mice to clock gene induction by light, mPer expression was assayed in the SCN following pulses of monochromatic light. Animals $(\mathrm{n}=12$ for each genotype) were kept for 20 days in a 12L/12D cycle and then transferred to DD for at least 10 days before light stimulation. Animals were exposed to a single monochromatic light pulse of an equivalent irradiance of $2.8 \times 10^{14}$ photons $/ \mathrm{cm}^{2} / \mathrm{s}$ using either 480- or 530-nm wavelength at one of the three durations $(1,5$, and $15 \mathrm{~min}$ ) that were applied in the study of behavioral phase shift. One hour after the beginning of the light pulse, mice were sacrificed by cervical dislocation under dim red light, and the brains were removed and immediately immersed in ice-cold $4 \%$ paraformaldehyde (PFA) and fixed at $4^{\circ} \mathrm{C}$ overnight. Brains were then dehydrated with ethanol $(30 \%, 50 \%$, and $70 \%, 2 \mathrm{~h}$ each, and $100 \%$ for $4 \mathrm{~h}$ at $4^{\circ} \mathrm{C}$ ) and transferred to xylene at room temperature. Xylene was changed once before being replaced by $50 \%$ xylene $/ 50 \%$ paraffin. Then, tissue was placed in paraffin, which was exchanged three times at $63^{\circ} \mathrm{C}$ before pouring it in embedding blocks. Coronal sections $(7 \mu \mathrm{m})$ of the mouse brain were made and fixed in $4 \%$ PFA, rinsed twice with phosphate-buffered saline (PBS; 5 min), followed by proteinase $\mathrm{K}(20 \mu \mathrm{g} / \mathrm{mL}$ in $50 \mathrm{mM}$ Tris-Hcl [pH 7.6] including $5 \mathrm{mM}$ EDTA) for $5 \mathrm{~min}$ at $37^{\circ} \mathrm{C}$. Sections were then rinsed once with PBS (5 min), 4\% PFA for $20 \mathrm{~min}$, then acetylated twice in $0.1 \mathrm{M}$ TEA, and washed again with PBS and dehydrated in a graded ethanol series. In situ hybridization was performed overnight with either denatured antisense or sense riboprobe for $m P e r 1$ and $m P e r 2$, as previously described (Albrecht 
(New England Nuclear, Charlotte, NC, USA) in a humid chamber at $55^{\circ} \mathrm{C}$. After hybridization, sections were then rinsed with $5 \times \operatorname{SSC}(0.75 \mathrm{M}$ $\mathrm{NaCl}, 0.075 \mathrm{M}$ sodium citrate), treated with $10 \mu \mathrm{g} / \mathrm{mL}$ ribonuclease $\mathrm{A}$ at $37^{\circ} \mathrm{C}$ for $30 \mathrm{~min}$, rinsed with stringency washes of SSC $(2 \times$ to $0.1 \times \mathrm{SSC})$, dehydrated in a graded ethanol series, dried, and exposed to Hyperfilm for 1-4 days. For each animal, all sections from the rostral to the caudal SCN were divided into two series to assess the light induction of mPerl and mPer2 in the same animal. Tissue was visualized by fluorescence of Hoechst dye-stained nuclei (not shown). Silver grains were visualized by dark-field illumination. Images were captured using a Spot II camera and software system.

Quantification was performed by densitometry analysis of hybridization signals of mPer1 and mPer2 using computer-assisted image analysis (Biocom, Les Ulis, France). Optical density of label was measured bilaterally from digitized images of the SCN. This method, previously described (Dkhissi-Benyahya et al., 2000; Rieux et al., 2002), is based on quantification of the total optical density of the labeling, defined as the integral sum of the surface area of all pixels in the SCN multiplied by their corresponding optical density value. The optical density of specific signal was calculated by subtracting the background density value determined from an adjacent area of the hypothalamus that did not contain staining. The background for each animal was systematically measured, and a threshold value was determined for detection of label significantly above the background level. Measures were made bilaterally, and every section of the SCN of each series was analyzed and averaged for each animal. The identity of the individual animals was unknown to the observer during the analysis.

\section{Statistical Analyses}

Significant differences between the response among genotypes and light-duration conditions were determined using a two-way analysis of variance (ANOVA), followed, when significant $(p<0.05)$, by post hoc Student Newman-Keuls to evaluate the differences in clock gene mRNA expression and phase-shift amplitude between genotypes for each duration. Values are shown as mean \pm SEM.

\section{RESULTS}

\section{Temporal Responses to Light-Induced Phase Shifts Are Altered in MW-Coneless Mice}

To examine the effects of the absence of MW-cones on light-induced phase shifts, we exposed animals to a pulse of monochromatic light at 
(Figure 1). In Figure 1, we include data from the 480-nm phase shifts reported previously (Dkhissi-Benyahya et al., 2007; enclosed in shaded square). In both genotypes, the shortest-duration light exposure used $(1 \mathrm{~min})$ at $360 \mathrm{~nm}$ induced a significant phase shift in comparison with the dark-control condition $(0.22 \pm 0.02 \mathrm{~h}$ for wild-type mice; $0.21 \pm$ $0.02 \mathrm{~h}$ for $\mathrm{MW}$-coneless mice). With longer durations of UV light exposure (from 1 to $15 \mathrm{~min}$ ), the magnitude of the phase shift increased proportionately in the two groups of mice. No significant differences in the magnitude of the phase shift of locomotor activity were observed between MW-coneless and wild-type mice for the three light durations tested at this wavelength (Figure 1).

At $480 \mathrm{~nm}$ and for the irradiance level of $2.8 \times 10^{14}$ photons $/ \mathrm{cm}^{2} / \mathrm{s}$, both genotypes showed significant phase shifts compared to dark controls starting with the short 1-min light pulse, and there was a significant increase in the response with increase of the exposure duration from 1 to 15 min (Figure 1). However, MW-coneless mice showed significantly attenuated phase shifts compared to wild-type mice for the exposure durations of 1 and $5 \mathrm{~min}(p<0.05$; Figure 1). For the 15 -min light exposure, equivalent phase shifts were induced in the two groups of mice.

At $530 \mathrm{~nm}$, the 1-min-duration pulse was insufficient to induce a significant phase shift compared to dark controls in either wild-type and MW-coneless mice (Figure 1), indicating that for this wavelength the irradiance used $\left(2.8 \times 10^{14}\right.$ photons $\left./ \mathrm{cm}^{2} / \mathrm{s}\right)$ was below the threshold to elicit
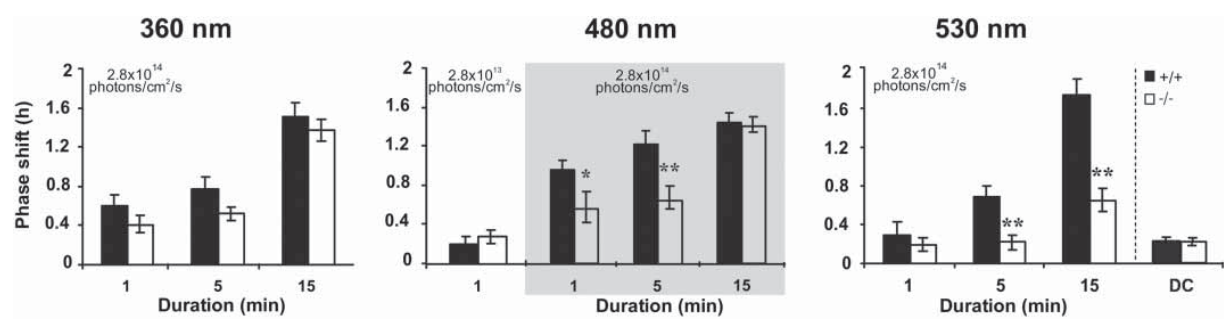

FIGURE 1 Attenuated phase-shifting response to light in MW-coneless mice. Mean phase shifts ( \pm SEM) in wild-type $(+/+)$ and MW-coneless $(-/-)$ mice $(n=8$ for each genotype) for the three light durations tested $(1,5$, and $15 \mathrm{~min})$ at $360,480,530 \mathrm{~nm}$ at an equal irradiance of $2.8 \times 10^{14}$ photons $/ \mathrm{cm}^{2} / \mathrm{s}$. An additional $1 \mathrm{log}$ unit lower irradiance level was tested at $480 \mathrm{~nm}$. Data in the shaded part of the histogram at $480 \mathrm{~nm}$ are from Dkhissi-Benyahya et al. (2007). A significant difference between genotypes is observed for light pulses of short duration (1 and $5 \mathrm{~min}$ ) at $480 \mathrm{~nm}$ and at $530 \mathrm{~nm}$ for durations of 5 and $15 \mathrm{~min}$. No differences between genotype were observed for the three durations at $360 \mathrm{~nm}$. Dark controls (DC), handled in the same way but that did not receive a light pulse, show no significant difference between genotypes $(0.22 \pm 0.02 \mathrm{~h}$ for wild-type mice; $0.21 \pm$ $0.02 \mathrm{~h}$ for $\mathrm{MW}$-coneless mice). Asterisks indicate a statistically significant difference between the two genotypes (ANOVA: $p<0.05$; post hoc Newman-Keuls tests comparing genotypes at each duration: $\left.{ }^{*} p<0.05 ;{ }^{* *} p<0.01\right)$. 
wild-type mice but was still insufficient to induce a phase shift in the MW-coneless mice. At the longest duration (15 min), light pulses of $530 \mathrm{~nm}$ induced significant phase shifts in both groups, but the phase shift of MW-coneless mice was significantly attenuated compared to that of the wild-type mice (Figure 1).

We speculated that the difference in the phase shift observed for the 1-min pulse at $480 \mathrm{~nm}$ but not at $530 \mathrm{~nm}$ could be due to the higher sensitivity of the circadian system in the mid-wavelength region of the spectrum (Lucas et al., 2003; Dkhissi-Benyahya et al., 2007). Thus, we additionally exposed the mice to a short 1-min pulse at $480 \mathrm{~nm}$ but used a $1 \log$ unit lower irradiance $\left(2.8 \times 10^{13}\right.$ photons $/ \mathrm{cm}^{2} / \mathrm{s}$; Figure 1$)$. In this case, however, neither genotype showed a significant phase shift $(0.20 \pm$ $0.08 \mathrm{~h}$ for wild-type mice and $0.28 \pm 0.07 \mathrm{~h}$ for MW-coneless mice), indicating the photon dose was below threshold (as was the case for the 1-min light pulse duration of higher irradiance exposure at $530 \mathrm{~nm}$ ).

We then used these data to model the response functions for stimulus durations at the different wavelengths. Figure 2a shows a composite graph of the phase-shift responses for both genotypes for the three light durations and three wavelengths tested. These data were then fit using a four-parameter logistic function to obtain dose-response curves (Figure 2b). As we did not assume that the response would be univariant (Dkhissi-Benyahya et al., 2007; Thompson et al., 2008), the best fit was obtained by calculating these functions separately for each genotype (see further details in figure legend). Half-saturation (duration necessary to induce $50 \%$ of the maximum response) values for each dose-response curve were obtained (Figure 2c), and the differences in the time required to attain the half-saturation response between the two genotypes were plotted (Figure 2d). At short and mid wavelengths, the difference between genotypes in the time required for half-saturation was short $(360 \mathrm{~nm}=4.2 \mathrm{~min} ; 480 \mathrm{~nm}=5.6 \mathrm{~min})$, but for the longer wavelength $(530 \mathrm{~nm})$ it was extremely long $(38.6 \mathrm{~min})$, indicating a relative decrease in photic sensitivity that increases at longer wavelengths in mice lacking MW-cones.

\section{Photic Induction of $m P e r$ Genes in the SCN of Wild-Type and MW-Coneless Mice}

In order to determine if light induction of clock genes are also altered by the absence of MW-cones, we exposed mice to equal irradiance $\left(2.8 \times 10^{14}\right.$ photons $\left./ \mathrm{cm}^{2} / \mathrm{s}\right)$ light pulses of 480 and $530 \mathrm{~nm}$ using the three light-exposure durations (1, 5, and $15 \mathrm{~min}$; Figure 3a, 3b). Since with the $360 \mathrm{~nm}$ light pulses no differences in phase-shift responses were observed between genotypes (Figure 1), we decided to focus on the 


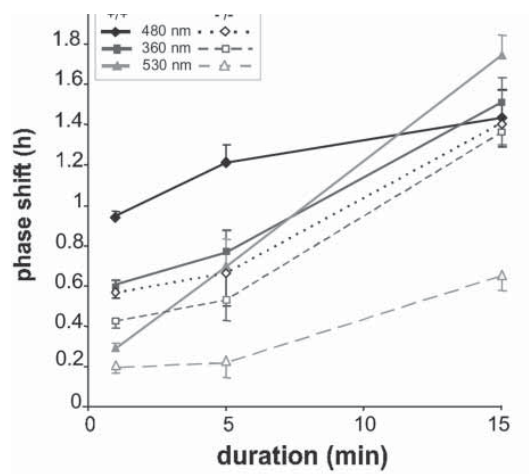

(C)

\begin{tabular}{cccc} 
& \multicolumn{3}{c}{ Half-saturation value } \\
& $(\mathbf{m i n})$ & \\
\hline Wavelength $(\mathbf{n m})$ & $\mathbf{3 6 0}$ & $\mathbf{4 8 0}$ & $\mathbf{5 3 0}$ \\
\hline Wild-type & 5.31 & 1.78 & 5.92 \\
MW-coneless & 9.57 & 7.38 & 44.58 \\
\hline
\end{tabular}

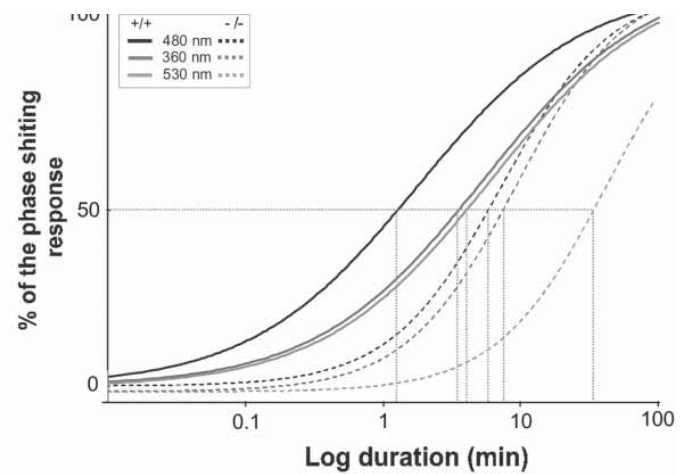

(D)

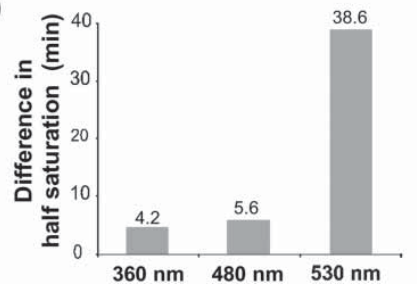

FIGURE 2 Reduced sensitivity to light in MW-coneless mice. (a) Plots of mean phase shifts ( \pm SEM, data from Figure 1) for different light durations (1, 5, $15 \mathrm{~min}$ ) and wavelengths (360, 480, $530 \mathrm{~nm}$ ) in wild-type $(+/+)$ and MW-coneless mice $(-/-)$. (b) Dose-response curves calculated using a four-parameter logistic function. For all curves, the minimum was set to the mean value of the dark controls $(0.22 \mathrm{~h})$ and the maximum to the mean values of phase shifts for a 15 -min pulse at the three wavelengths $(1.56 \mathrm{~h})$. This maximum corresponds to the mean saturation value of phase shifts at the three wavelengths and for the irradiance level of $2.8 \times 10^{14}$ photons $/ \mathrm{cm}^{2} / \mathrm{s}$. The slope was determined separately for each genotype, using the averaged data for 360 and $480 \mathrm{~nm}$ and is slightly different in wild-type (0.72) and MW-coneless (1.08) mice. $R^{2}$ values varied from 0.82 to 0.97 . (c) Half-saturation values for wild-type and for MW-coneless mice at the three wavelengths. (d) Histogram illustrate the differences between the two genotypes in half saturation values for each wavelength.

photic induction of mPer genes for wavelengths that showed alteration of the behavioral response in the MW-coneless mice.

Similar to observations for the behavioral phase shifts, mPerl and $m$ Per 2 mRNAs were significantly induced, compared to the background level, by the 480-nm light pulse for the three durations in both genotypes (Figure 3a). Although mPerl gene expression did not increase with increased light duration $(p=0.45)$, mPer 2 mRNA expression increased significantly from 1 to 15 min $(p<0.05$ in wild-type mice and $p<0.005$ in MW-coneless mice; Figure 3b). At $480 \mathrm{~nm}$, a significant difference between genotypes was observed only for mPerl following the 5-min pulse $(p<0.05)$.

The 530-nm light pulse of 1-min duration did not induce mPer1 and $m$ Per 2 above background levels in both groups. Increasing the duration of the light pulse from 1 to 15 min produced significant photic induction 

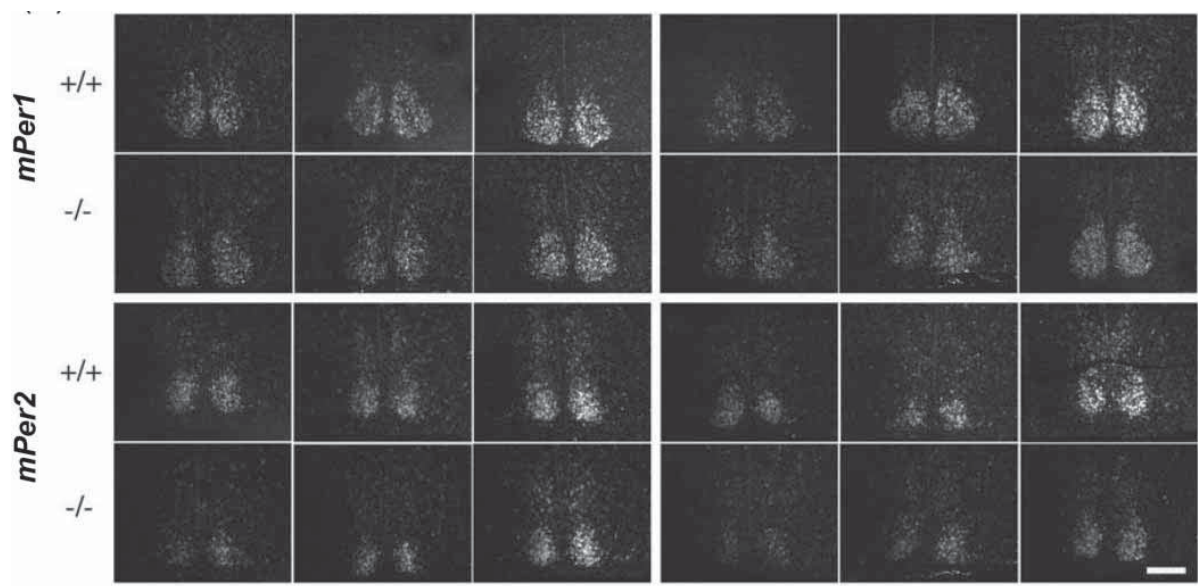

$1 \mathrm{~min}$

5 min

$15 \mathrm{~min}$

1 min

5 min

$15 \mathrm{~min}$

(B)
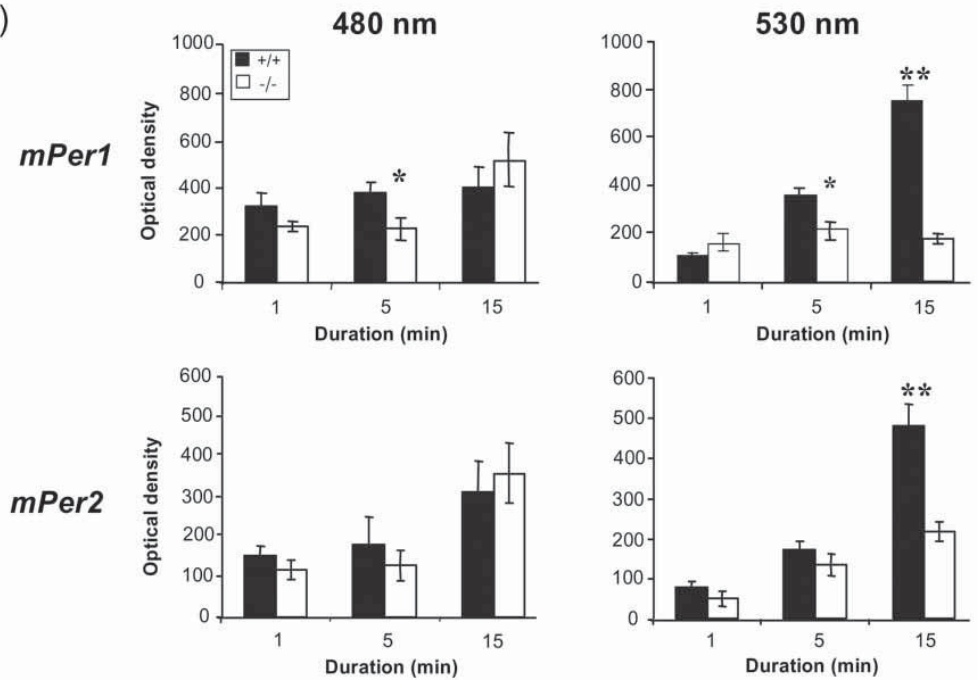

FIGURE 3 Induction of mPer 1 and mPer 2 in the SCN of wild-type $(+/+)$ and MW-coneless $(-/-$ ) mice by monochromatic light $(480 \mathrm{~nm}$ or $530 \mathrm{~nm})$ of different pulse durations $(1,5$, and $15 \mathrm{~min})$ at a constant irradiance level of $2.8 \times 10^{14}$ photons $/ \mathrm{cm}^{2} / \mathrm{s}(\mathrm{n}=12$ for each genotype). (a) Representative photographs of mPer 1 and mPer 2 mRNA in situ hybridization in the SCN $60 \mathrm{~min}$ following the initial exposure to light delivered at CT16. (b) Quantification of $m$ Per 1 and mPer $2 \mathrm{mRNA}$ levels from in situ hybridization data from wild-type $(+/+)$ and MW-coneless $(-/-)$ mice. Results are expressed as mean \pm SEM. Asterisks indicate a statistically significant difference (ANOVA: $p<0.05$; post hoc Newman-Keuls tests comparing genotypes at each duration: $\left.{ }^{*} p<0.05 ;{ }^{* *} p<0.001\right)$.

of both mPer 1 and mPer 2 in wild-type mice $(p<0.001$ for both genes), whereas in $\mathrm{MW}$-coneless mice only $m P e r 2$ expression significantly increased. The MW-coneless mice showed a significant reduction in $m P e r 1$ expression for the 5-min light exposure and for both mPerl and $m$ Per2 for the 15-min light exposure (15 min, $p<0.0001)$. 
Several studies have provided convincing evidence that cones play a role in circadian entrainment and in SCN neuronal responses to light (Aggelopoulos \& Meissl, 2000; Hattar et al., 2003; Lucas et al., 2003; Dacey et al., 2005; Dkhissi-Benyahya et al., 2007; Drouyer et al., 2007), pupil constriction (Lucas et al., 2003), masking (Thompson et al., 2008), and sleep induction (Altimus et al., 2008). Our previous study (DkhissiBenyahya et al., 2007) had shown that the specific absence of MW-cones alters phase-shifting responses for different irradiances. The present results extend these findings by demonstrating that in the absence of MW-cones, light-induced phase shifts and mPer1 and mPer2 mRNA induction in the SCN are attenuated in an exposure-duration- and wavelength-dependent manner. These alterations in sensitivity are not likely to be due to an absence of the nuclear thyroid hormone receptors per se, since the differences in responsiveness are wavelength dependent, and the MW-coneless mice display normal responses in the UV region of the spectrum.

\section{Phase-Shifting Responses to Monochromatic Light Are Altered in MW-Coneless Mouse}

Although both wild-type and MW-coneless mice show increased responses to longer-duration light exposures, the absence of MW-cones results in attenuated behavioral responses and a general decrease in sensitivity that is wavelength dependent. At $480 \mathrm{~nm}$, the deficits in MW-coneless mice are observed for the 1- and 5-min durations, whereas at $530 \mathrm{~nm}$ deficits are observed for the 5- and 15-min durations. For the 530-nm stimulations and at the irradiance level used $\left(2.8 \times 10^{14}\right.$ photons $\left./ \mathrm{cm}^{2} / \mathrm{s}\right)$, the 1-min light pulse was below threshold for both genotypes, since the phase shifts are not significantly different from that of dark controls. Above this threshold level, a deficit in the phase shift for the MW-coneless mice is first observed with the 5-min duration. Since the peak of MWcone sensitivity is at $508 \mathrm{~nm}$ (longer than the peak sensitivity of melanop$\sin$ at $480 \mathrm{~nm}$ ), the difference in the responses between the wild-type and MW-coneless mice with the 5- and 15-min exposures is also related to the proportionately greater contribution of $\mathrm{MW}$-cones at this wavelength (Dkhissi-Benyahya et al., 2007). One might thus speculate that the responses to a 1-min pulse but at a higher irradiance would have induced significantly different phase shifts in the two genotypes. On the contrary, at $480 \mathrm{~nm}$, the 15 -min-duration light pulse produced equivalent saturation level responses in both genotypes (Dkhissi-Benyahya et al., 2007), whereas at $530 \mathrm{~nm}$ only the wild-type mice attained a saturating response. Since the half-saturation value at $530 \mathrm{~nm}$ is $\sim 44 \mathrm{~min}$ (Figure 2c), it could 
to attain a saturating response.

These results are consistent with the view that melanopsin ipRGCs provides a sustained signal throughout the duration of the light stimulus and for long temporal integration, whereas cones contribute during the initial part of the response due to their phasic response at light-onset (Berson et al., 2002; Dacey et al., 2005; Tu et al., 2005; Dkhissi-Benyahya et al., 2007; Drouyer et al., 2007; Mure et al., 2007; Wong et al., 2007; Schmidt et al., 2008). In these electrophysiological studies, a high-amplitude, shortduration phasic input originating from cones (and eventually rods) occurs within the first $500 \mathrm{~ms}$ following light-onset. In contrast, the sustained melanopsin response appears after a delay ranging from seconds to minutes depending on light intensity (Berson et al., 2002; Dacey et al., 2005; Tu et al., 2005; Dkhissi-Benyahya et al., 2007; Drouyer et al., 2007; Mure et al., 2007; Wong et al., 2007; Schmidt et al., 2008). In line with this hypothesis, we have previously shown that bright-light exposures aimed at desensitizing rods and cones will abolish the initial phasic SCN responses while minimally affecting the sustained melanopsin components (Drouyer et al., 2007), whereas melanopsin-invalidated mice conserve robust phasic responses but lack the sustained components (Mure et al., 2007). For downstream responses involving sensory and/or motor integration, phasic and sustained components may be expressed on a more extended time scale. This is observed, for example, in pupillary constriction (Gamlin et al, 2007; Mure et al., 2009) or in masking (Mrosovsky \& Hattar, 2003), where in the $\mathrm{Opn}_{4}^{-/-}$mouse cones and rods are unable to maintain the response under continuous light in the absence of sustained input from melanopsin ipRGCs.

In our experiments, the initial phasic influence of MW-cones is particularly obvious for the 1-min-duration light pulse at $480 \mathrm{~nm}$ where, based on the difference in response amplitude between the two genotypes, cones appear to account for nearly $50 \%$ of the response (Figure 1). Furthermore, a 5-fold increase in duration of light exposure from 1 to 5 min only produces a $25 \%$ (non-significant) increase.

The absence of MW-cones does not affect phase-shifting responses at $360 \mathrm{~nm}$, although relative sensitivity is slightly reduced, since the calculated dose-response curve is shifted to longer durations (Figure 2b). This result is coherent with the greatly reduced relative sensitivity of $\mathrm{MW}$ cones at this wavelength $(\sim 2 \log$ units $)$ and implies that short-wavelength cones and, perhaps, melanopsin account for behavioral phase-shift responses in the UV region of the spectrum. Since the relative sensitivity of melanopsin is also reduced in the $U V$ region $(\sim 1.5 \log$ units $)$, the robust phase-shift response is due either to a relatively large contribution of the short-wavelength (SW)-cones (Thompson et al., 2008) or their possible priming effect on the intrinsic response of ipRGCs for which this 
of this priming effect could represent a form of spectral "interaction" that widens the wavelength sensitivity output of ipRGCs in both the UV region (via UV-cones) and to longer wavelengths (via MW-cones). A priming effect between outer retinal photoreceptors and melanopsin, first suggested by Dacey et al. (2005) and Wong et al. (2007), has recently been experimentally demonstrated by Schmidt et al. (2008), who showed that synaptic input from MW-cones confers to ipRGCs a higher overall light sensitivity and a shift in spectral sensitivity from $480 \mathrm{~nm}$ towards longer wavelengths.

\section{Light Induction of $m P e r 1$ and $m P e r 2$ in the SCN Is Altered in MW-Coneless Mouse}

Direct photic input to the SCN leads to the induction of clock genes, including Per1 and Per2 (Hamada et al., 2001; Yan \& Silver, 2002). However, specific wavelength and light-duration-dependent effects on mPer gene expression have not been examined previously. We show here that the absence of MW-cones affects the photic induction of $m P e r 1$ and $m P e r 2$ in the SCN of MW-coneless mice in a pattern that is consistent with the observed effects of 480-and 530-nm light pulses on behavioral phase shifts. Following 530-nm light stimulations, significant differences in $m$ Per 1 expression between the genotypes were observed for both the 5and 15-min exposures but not for the 1-min exposure (below threshold), in agreement with the behavioral results. At $480 \mathrm{~nm}$, a significant difference in $m P e r 1$ expression was only observed for the 5-min light exposure, whereas an expected difference for the 1-min exposure was not observed. At $530 \mathrm{~nm}$, the 15 -min light pulse induced equivalent amounts of $m P e r 1$ expression and phase shift; $m$ Per2 induction by light is less affected by the absence of MW-cones, and a significantly reduced expression is only seen at the longest duration used (15 min).

Our study differs from the only previous one that examined the consequences of photoreceptor loss on photic induction of clock genes in the SCN, which reported a similar induction of mPER1 protein in wildtype and $r d / r d$ mice (Alvarez-Lopez et al., 2006) . This discrepancy could be related to the experimental design (30-min stimulation of white light versus 1, 5, and 15 monochromatic light pulses), the photoreceptor mutation $(r d / r d$ or MW-coneless mice), and/or gene versus protein assay.

In conclusion, our results confirm the view that circadian photoreception is based on multiple photoreceptors functioning in concert within a system where each photoreceptor provides specific contributions based on its response domain and the photic environment in terms of the spectrum, irradiance, and duration of light. Although cones are not necessary for circadian entrainment and gene expression, their presence is required 
respond to a range of light intensities and durations. For example, phasic responses from cones to light-onset may account for the greater efficiency of multiple short-duration light pulses to shift the human circadian timing system compared to a single long-duration exposure of higher total irradiance (Gronfier et al., 2007). By providing a phasic input to the mid-wavelength region of the spectrum, MW-cones increase the overall sensitivity of the system, shift the response to longer wavelengths, and widen the spectral bandwidth. The same is most likely valid for the SWcone contribution in the short-wavelength region of the spectrum.

Declaration of interest: The authors report no conflicts of interest. The authors alone are responsible for the content and writing of the paper.

\section{REFERENCES}

Aggelopoulos NC, Meissl H. (2000). Responses of neurones of the rat suprachiasmatic nucleus to retinal illumination under photopic and scotopic conditions. J. Physiol. (Lond.) 523(Pt 1):211-222.

Albrecht U, Sun Z, Eichele G, Lee C. (1997). A differential response of two putative mammalian circadian regulators, mper1 and mper2, to light. Cell 91:1055-1064.

Altimus CM, Guler AD, Villa KL, McNeill DS, Legates TA, Hattar S. (2008). Rods-cones and melanopsin detect light and dark to modulate sleep independent of image formation. Proc. Natl. Acad. Sci. U. S. A. 105:19998-20003.

Alvarez-Lopez C, Cernuda-Cernuda R, Garcia-Fernandez JM. (2006). The mPerl clock gene expression in the rd mouse suprachiasmatic nucleus is affected by the retinal degeneration. Brain Res. 1087:134-141.

Belenky MA, Smeraski CA, Provencio I, Sollars PJ, Pickard GE. (2003). Melanopsin retinal ganglion cells receive bipolar and amacrine cell synapses. J. Comp. Neurol. 460:380-393.

Berson DM, Dunn FA, Takao M. (2002). Phototransduction by retinal ganglion cells that set the circadian clock. Science 295:1070-1073.

Dacey DM, Liao HW, Peterson BB, Robinson FR, Smith VC, Pokorny J, Yau KW, Gamlin PD. (2005). Melanopsin-expressing ganglion cells in primate retina signal colour and irradiance and project to the LGN. Nature 433:749-754.

Dkhissi-Benyahya O, Gronfier C, De Vanssay W, Flamant F, Cooper HM. (2007). Modeling the role of mid-wavelength cones in circadian responses to light. Neuron 53:677-687.

Dkhissi-Benyahya O, Sicard B, Cooper HM. (2000). Effects of irradiance and stimulus duration on early gene expression (Fos) in the suprachiasmatic nucleus: temporal summation and reciprocity. J. Neurosci. 20:7790-7797.

Drouyer E, Dkhissi-Benyahya O, Chiquet C, WoldeMussie E, Ruiz G, Wheeler LA, Denis P, Cooper HM. (2008). Glaucoma alters the circadian timing system. PLoS ONE 3:e3931.

Drouyer E, Rieux C, Hut RA, Cooper HM. (2007). Responses of suprachiasmatic nucleus neurons to light and dark adaptation: relative contributions of melanopsin and rod-cone inputs. J. Neurosci. 27:9623-9631.

Ebihara S, Tsuji K. (1980). Entrainment of the circadian activity rhythm to the light cycle: effective light intensity for a Zeitgeber in the retinal degenerate $\mathrm{C} 3 \mathrm{H}$ mouse and the normal C57BL mouse. Physiol. Behav. 24:523-527.

Forrest D, Hanebuth E, Smeyne RJ, Everds N, Stewart CL, Wehner JM, Curran T. (1996). Recessive resistance to thyroid hormone in mice lacking thyroid hormone receptor beta: evidence for tissue-specific modulation of receptor function. EMBO J. 15:3006-3015. 
macaque pupı responses arıven dy meranopsin-contamng reunal gangiın cens. viston kes. 47:946-954.

Gauthier K, Chassande O, Plateroti M, Roux JP, Legrand C, Pain B, Rousset B, Weiss R, Trouillas J, Samarut J. (1999). Different functions for the thyroid hormone receptors TRalpha and TRbeta in the control of thyroid hormone production and post-natal development. EMBO $\mathrm{J}$. 18:623-631.

Hamada T, LeSauter J, Venuti JM, Silver R. (2001). Expression of Period genes: rhythmic and nonrhythmic compartments of the suprachiasmatic nucleus pacemaker. J. Neurosci. 21:7742-7750.

Hattar S, Liao HW, Takao M, Berson DM, Yau KW. (2002). Melanopsin-containing retinal ganglion cells: architecture, projections, and intrinsic photosensitivity. Science 295:1065-1070.

Hattar S, Lucas RJ, Mrosovsky N, Thompson S, Douglas RH, Hankins MW, Lem J, Biel M, Hofmann F, Foster RG, Yau KW. (2003). Melanopsin and rod-cone photoreceptive systems account for all major accessory visual functions in mice. Nature 424:75-81.

Lucas RJ, Douglas RH, Foster RG. (2001). Characterization of an ocular photopigment capable of driving pupillary constriction in mice. Nat. Neurosci. 4:621-626.

Lucas RJ, Hattar S, Takao M, Berson DM, Foster RG, Yau KW. (2003). Diminished pupillary light reflex at high irradiances in melanopsin-knockout mice. Science 299:245-247.

Mrosovsky N. (2003). Contribution of classic photoreceptors to entrainment. J. Comp. Physiol. A Neuroethol. Sens. Neural Behav. Physiol. 189:69-73.

Mrosovsky N, Hattar S. (2003). Impaired masking responses to light in melanopsin-knockout mice. Chronobiol. Int. 20:989-999.

Mrosovsky N, Hattar S. (2005). Diurnal mice (Mus musculus) and other examples of temporal niche switching. J. Comp. Physiol. A Neuroethol. Sens. Neural Behav. Physiol. 191:1011-1024.

Mure LS, Rieux C, Hattar S, Cooper HM. (2007). Melanopsin-dependent nonvisual responses: evidence for photopigment bistability in vivo. J. Biol. Rhythms 22:411-424.

Mure LS, Cornut PL, Rieux C, Drouyer E, Gronfier C, Denis P, Cooper HM. (2009). Melanopsin bistabiliy: a fly's eye technology in the human retina. PLOS ONE 4:e5991.

Panda S, Provencio I, Tu DC, Pires SS, Rollag MD, Castrucci AM, Pletcher MT, Sato TK, Wiltshire T, Andahazy M, Kay SA, Van Gelder RN, Hogenesch JB. (2003). Melanopsin is required for nonimage-forming photic responses in blind mice. Science 301:525-527.

Panda S, Sato TK, Castrucci AM, Rollag MD, DeGrip WJ, Hogenesch JB, Provencio I, Kay SA. (2002). Melanopsin (Opn4) requirement for normal light-induced circadian phase shifting. Science 298:2213-2216.

Portaluppi F, Touitou Y, Smolensky MH. (2008). Ethical and methodological standards for laboratory and medical biological rhythm research. Chronobiol. Int. 25:999-1016.

Rieux C, Carney R, Lupi D, Dkhissi-Benyahya O, Jansen K, Chounlamountri N, Foster RG, Cooper HM. (2002). Analysis of immunohistochemical label of Fos protein in the suprachiasmatic nucleus: comparison of different methods of quantification. J. Biol. Rhythms 17:121-136.

Schmidt TM, Taniguchi K, Kofuji P. (2008). Intrinsic and extrinsic light responses in melanopsinexpressing ganglion cells during mouse development. J. Neurophysiol. 100:371-384.

Sun H, Gilbert DJ, Copeland NG, Jenkins NA, Nathans J. (1997). Peropsin, a novel visual pigmentlike protein located in the apical microvilli of the retinal pigment epithelium. Proc. Natl. Acad. Sci. U. S. A. 94:9893-9898.

Thompson S, Foster RG, Stone EM, Sheffield VC, Mrosovsky N. (2008). Classical and melanopsin photoreception in irradiance detection: negative masking of locomotor activity by light. Eur. J. Neurosci. 27:1973-1979.

Tu DC, Zhang D, Demas J, Slutsky EB, Provencio I, Holy TE, Van Gelder RN. (2005). Physiologic diversity and development of intrinsically photosensitive retinal ganglion cells. Neuron 48:987-999.

Viney TJ, Balint K, Hillier D, Siegert S, Boldogkoi Z, Enquist LW, Meister M, Cepko CL, Roska B. (2007). Local retinal circuits of melanopsin-containing ganglion cells identified by transsynaptic viral tracing. Curr. Biol. 17:981-988.

Wong KY, Dunn FA, Graham DM, Berson DM. (2007). Synaptic influences on rat ganglion-cell photoreceptors. J. Physiol. 582:279-296.

Yan L, Silver R. (2002). Differential induction and localization of mPer1 and mPer2 during advancing and delaying phase shifts. Eur. J. Neurosci. 16:1531-1540. 